\section{Freshness Indices of Roasted Coffee: Monitoring the Loss of Freshness for Single Serve Capsules and Roasted Whole Beans in Different Packaging}

\author{
Alexia N. Glössª , Barbara Schönbächlera, Markus Rast ${ }^{\mathrm{b}}$, \\ Louis Deuber ${ }^{c}$, and Chahan Yeretzian ${ }^{\star a}$ \\ ${ }^{*}$ Correspondence: Prof. Dr. C. Yeretzian ${ }^{a}$ \\ Tel.: +415893455 26, E-mail: yere@zhaw.ch \\ a Zurich University of Applied Sciences, Institute of Chemistry and Biological Che- \\ mistry, $\mathrm{CH}-8820$ Wädenswil \\ Rast Kaffee AG, 6031 Ebikon, Switzerland \\ 'Luna Technology Systems LTS GmbH, Wallisellen, Switzerland
}

Abstract: With the growing demand for high-quality coffee, it is becoming increasingly important to establish quantitative measures of the freshness of coffee, or the loss thereof, over time. Indeed, freshness has become a critical quality criterion in the specialty coffee scene, where the aim is to deliver the most pleasant flavor in the cup, from highest quality beans. A series of intensity ratios of selected volatile organic compounds (VOC) in the headspace of coffee (by gas chromatography-mass spectrometry) were revisited, with the aim to establish robust indicators of freshness of coffee - called freshness indices. Roasted whole beans in four different packaging materials and four commercial capsule systems from the Swiss market were investigated over a period of up to one year of storage time. These measurements revealed three types of insight. First, a clear link between barrier properties of the packaging material and the evolution of selected freshness indices was observed. Packaging materials that contain an aluminum layer offer better protection. Second, processing steps prior to packaging are reflected in the absolute values of freshness indices. Third, differences in the standard deviations of freshness-indices for single serve coffee capsule systems are indicative of differences in the consistency among systems, consistency being an important quality attribute of capsules.

Keywords: Coffee · Freshness · Gas chromatography · Single serve capsule systems

\section{Introduction}

Coffee is colloquially referred to as being a 'bean'. However, it is the seed of a fruit - not a bean. And unlike most fruits, it is the seed that is the valuable part, while the pulp is most often discarded. Once harvested and processed the beans have a water content of $10-12 \%$, and if properly stored they can be kept as green beans for a few years, without the quality of the final product, the cup of coffee, being affected. Yet, a green coffee bean has neither the typical coffee flavor, nor can it be readily ground and extracted. It is only once roasted that the precursors in the green bean react and generate the volatile ${ }^{[1-8]}$ and non-volatile compounds that together form the typical flavor of coffee. ${ }^{[9-17]}$ At the same time, the texture of the bean becomes brittle and can easily be ground and efficiently extracted. Many of the important coffee flavor compounds are yet known to be labile ${ }^{[18,19]}$ and/or highly volatile; $[20,21]$ as soon as they are generated in the roasting process they already start to degrade and evaporate off the coffee. The flavor of freshly roasted coffee is indeed very elusive ${ }^{[19,22]}$ leading to a rapid loss of freshness. The processes involved in such loss of freshness are complex and may occur via two main pathways: i) One is a loss of highly volatile compounds; ii) another is via chemical reactions, e.g. by oxidation with $\mathrm{O}_{2}$, or via intrinsic chemical reactions among coffee components. Many chemical classes (thiols, diones, aldehydes, vinyl derivatives) may react upon storage. This may lead to either a decrease or increase of headspace concentration for selected compounds. Hence the loss of freshness can best be described as a progressive imbalance in the aroma profile. Such processes have been extensively discussed in the literature, with the aim to identify markers for shelf-life of packaged roasted coffee. The first studies on coffee aroma deterioration can be traced back to the 1940s by A. C. Shuman, ${ }^{[23]}$ followed in the fifties by work from Merritt et al. ${ }^{[24]}$ and Buchner et al. ${ }^{[25]}$ Many more groups have addressed the shelf-life of roasted coffee beans or roast and ground (R\&G) coffee samples, either from a chemical or a sensory point of view (or both).[10,26-41]

Considering that coffee contains more than $10 \%$ of fat in the green beans, volatile lipid oxidation products have been an early focus in studies on degradation markers of coffee. Such studies reported a correlation of coffee staling with the generation of $n$ hexanal after an initiation phase of approximately seven weeks of storage in air. ${ }^{[26,42,43]}$ These studies have also shown that other products formed by oxidative degradation of unsaturated fatty acids in roasted coffee do not play a significant role in the flavor of roasted coffee. While hexanal seems to be the only notable exception, its formation cannot explain the loss of freshness, because a certain loss of odor intensity (freshness) is perceptible and a significant loss of cup quality noticeable already much earlier during storage. Hence, the increase of hexanal concentration occurs only at a quite advanced degree of staleness and is less relevant to address the freshness of specialty coffee.

Although several VOC markers were suggested to monitor freshness deterioration of $R \& G$ coffee, the major weakness of using absolute concentrations of such marker compounds to estimate freshness relates to the fact that the amount of any single compound depends, among others, on its initial concentration and is affected by variables such as blend, roast degree, grinding, extraction and others. ${ }^{[30]}$ The use of ratios of headspace concentrations of selected VOCs is therefore more robust, and reflects changes in the balance in the headspace. ${ }^{[26-28,30,44]}$

Here we have revisited many of the reported VOC ratios and selected four that are robust and suited to assess the freshness of high quality specialty coffee. We have termed these 'freshness indices'. The four freshness indices that will be discussed are: 2-butanone/2-methylfuran and 2,3-butanedione/2-methylfuran for whole beans and dimethyl disulfide/methanethiol and 2-butanone/methanethiol for capsule systems (R\&G).

Two types of samples were analyzed: i) whole roasted beans in four different packaging materials, ranging from a simple paper pack to a plastic composite film with a thick aluminum layer (250 g pack sizes); and ii) R\&G coffee, packed as individual single serve capsules (commercial products from Swiss market). 


\section{Material and Methods}

Freshly roasted coffea arabica from Guatemala, Antigua (La Ceiba) was packed in four different packaging materials, all equipped with valves, except paper: paper bag, plastic composite film (paper50/PE23), plastic composite film with thin aluminum layer (paper50/PE25/ALU7/PE35), and plastic composite film with thick aluminum layer (PET12MY/ALU8/PE90MY). Each package contained $250 \mathrm{~g}$ roasted whole beans and was stored at room temperature. The maximum storage time was 57 weeks. Single serve coffee capsules from four different leading commercial brands, labeled C1 to C4 (see Table 1) and available on the Swiss market, were analyzed. The capsules were stored at room temperature for up to 46 weeks.

Table 1. Description of the four different capsule systems, labelled C1 to C4 (first column). The second column describes the materials used as packaging materials for the cover and the body of the capsule. PP: polypropylene, EVOH: Ethylene vinyl alcohol.

\section{Code Material \\ - Body: PP/EVOH/PP \\ C1 - Cover: PP/EVOH/PP; thickness: $0.1 \mathrm{~mm}$ \\ - Barrier-properties integrated into capsule and cover \\ - Body: PP/EVOH/PP \\ - Cover: PP/EVOH/PP; thickness: $0.12 \mathrm{~mm}$ \\ C2 - Barrier-properties integrated into capsule and cover \\ - Extraction system (perforation points \& aluminum foil) and outlet for extract are integrated in cover- material \\ - Body: PP (injection molding without barrier- properties) \\ - Cover: Paper with aluminum coating; thickness: $0.03-0.05 \mathrm{~mm}$ \\ - Secondary packaging: aluminum; each capsule is individually packed; barrier-properties integrated into secondary packaging \\ - Body: 99\% aluminum, with thin coating of food- grade shellac \\ C4 \\ - Cover: aluminum foil; thickness 0.03-0.05 mm \\ - Barrier-properties integrated into capsule and cover}

Freshness was monitored via four freshness indices: 2-butanone/2-methylfuran and 2,3-butanedione/2-methylfuran for whole beans and dimethyl disulfide/methanethiol and 2-butanone/methanethiol for the capsules (R\&G).

In the case of the whole beans, one package per sample was opened freshly, the beans milled and $4 \mathrm{~g}$ of $\mathrm{R} \& \mathrm{G}$ powder immediately filled in headspace vials under nitrogen atmosphere. All measurements were performed in triplicate and values are expressed by their mean-values and standard deviation (Fig. 1).

For the single serve coffee capsules, each capsule was opened and $4 \mathrm{~g} \mathrm{R} \& \mathrm{G}$ powder immediately filled in a headspace vial under nitrogen atmosphere. All measurements were performed five-fold and values are expressed by their mean-values and standard deviation (Fig. 2).

Headspace GC-MS parameters are: sample incubation: 20 min at $70{ }^{\circ} \mathrm{C}$, headspace: $2.5 \mathrm{~mL}$ headspace syringe, $70{ }^{\circ} \mathrm{C}$, injection volume $1 \mathrm{~mL}$, (MPS2, Gerstel, Switzerland), GC/ MS: (7890/5975N, Agilent Technologies, Switzerland) injector temperature $250{ }^{\circ} \mathrm{C}$, split 30:1, DB-WAX $(30 \mathrm{~m} \times 250 \mu \mathrm{m} \times 0.25$ $\mu \mathrm{m})$, helium flow: $1 \mathrm{ml} / \mathrm{min}$, oven: $20^{\circ} \mathrm{C}$ for $6 \mathrm{~min}$, then $10{ }^{\circ} \mathrm{C} /$ min to $70{ }^{\circ} \mathrm{C}$ for $0 \mathrm{~min}$, then $5^{\circ} \mathrm{C} / \mathrm{min}$ to $170{ }^{\circ} \mathrm{C}$ for $0 \mathrm{~min}$ and then $40{ }^{\circ} \mathrm{C} / \mathrm{min}$ to $220^{\circ} \mathrm{C}$ for $0 \mathrm{~min}$.

\section{Results and Discussion}

In Fig.1 and Fig. 2, the evolution of the freshness ratios over time is shown for the whole beans as well as for the capsule systems.

For the whole beans stored in different packages, the ratios 2-butanone/2-methylfuran (Fig. 1a) and 2,3-butanedione/2methylfuran (Fig. 1b) were analyzed. The ratio 2-butanone/2methylfuran is probably the best known ratio for analyzing the shelf-life of coffee. An increase of this ratio was shown to be related to coffee staling. ${ }^{[26-28,45]}$ Both compounds are relatively stable in coffee regarding chemical reactions. However, 2-methylfuran is one of the most volatile compounds in coffee. Its concentration decreases rapidly, provided loss of 2-methylfuran through the packaging material is possible. Hence, this ratio is mainly driven by the high volatility of 2-methylfuran, increasing if the packaging material allows 2-methylfuran to evaporate. In contrast, with packaging that prevents the loss of 2-methylfuran, the ratio will mainly be governed by the small differences in intrinsic reactivity among the two compounds. Referring to Fig. 1a and Fig. 1b, we observe that the absence of an aluminum layer in the packaging material leads to an increase in this ratio, while packaging with aluminum layer show only very small changes over time. Already after two weeks the difference in the ratios for coffee packed with aluminum layer compared to no aluminium is

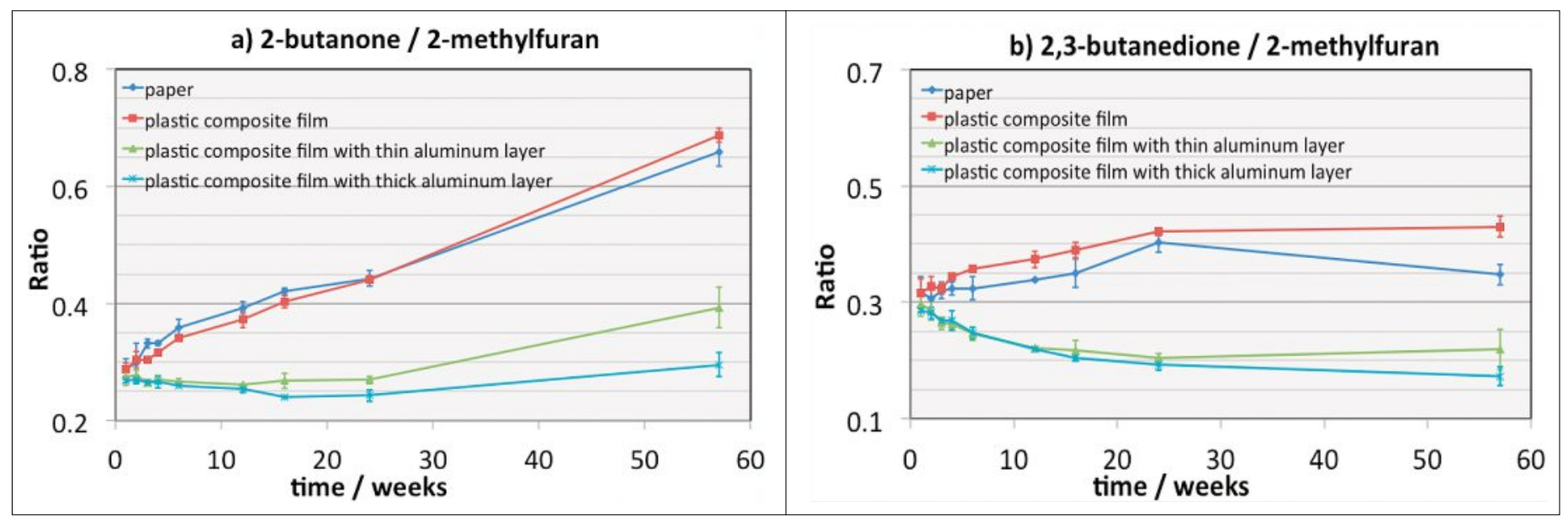

Fig. 1. Selected freshness indices (ratios of VOCs) are plotted as a function of storage time (up to 57 weeks) for roasted whole beans during storage in four different packaging materials. The error bars correspond to the respective standard deviation of the three-fold measurements. 


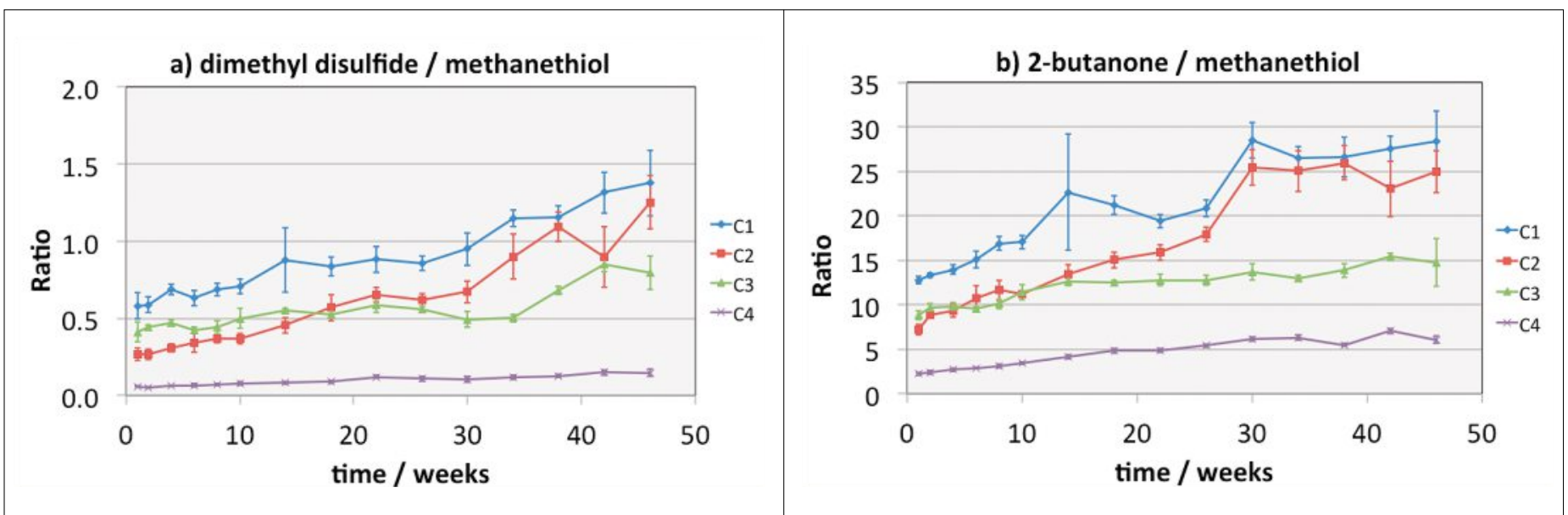

Fig. 2: Selected freshness indices (ratios of VOCs) are plotted as a function of storage time for R\&G coffee for four different commercial single serve coffee capsules, stored over a period of up to 46 weeks. The error bars correspond to the respective standard deviation of the five-fold measurements.

significantly different. Hence this freshness index is a sensitive and good marker for the gas permeability of packaging materials, and therefore for the loss of freshness.

The development of the ratio 2,3-butanedione/2-methylfuran as a function of the storage time of coffee is shown in Fig. 1b. It was observed that 2,3-butanedione decreased during storage of ground coffee. ${ }^{[28,29,46]}$ Referring to Fig. 1b, we again see a clear differentiation between packaging materials with or without an aluminum layer. For coffees packed in paper and plastic composite films, the ratio 2,3-butanedione/2-methylfuran increased with storage time. For packages with aluminum layer, we observed a slight decrease in this ratio, as it was observed by Kallio et al.[29] and Leino et al..$^{[30]}$ This can tentatively be attributed to a relatively higher reactivity of 2,3-butanedione, leading to a decrease in this freshness index, even with an aluminum layer. This is an indication of intrinsic reactivity, even without oxygen penetrating through the packaging material.

Hence the evolution of the freshness-indices 2-butanone/2methylfuran and 2,3-butanedione/2-methylfuran are mainly driven by the high volatility of 2-methylfuran, while the difference between the two ratios can be attributed to a slightly higher reactivity of 2,3-butanedione, relative to 2-butanone.

In Fig. 2a and b, the evolution of two other freshness indices is shown for single serve coffee capsules: a) dimethyl disulfide/methanethiol and b) 2-butanone/methanethiol. In both these freshness indices, methanethiol is the denominator. Methanethiol is known to be a highly volatile as well as reactive compound, $[16,32,42]$ reacting among others by oxidation and dimerization to dimethyl disulfide. ${ }^{[22,47]}$ In contrast, dimethyl disulfide and 2-butanone have both relatively lower reactivity and volatility. Consequently, the overall evolution of these two freshness indices is mainly driven by the high reactivity and volatility of methanethiol. A further intrinsic reaction of dimethyl disulfide to dimethyl trisulfide was not observed. Hence, these two freshness indices dimethyl disulfide/methanethiol and 2-butanone/methanethiol are essentially driven by the fast decrease in headspace concentration of methanethiol.

Referring to the evolution of dimethyl disulfide/methanethiol and 2-butanone/methanethiol (Fig. 2), the three main findings are: First and most importantly, an impact of the packaging material is obvious. The two capsules $\mathrm{C} 1$ and $\mathrm{C} 2$, which both do not have any aluminum layer, show the strongest increase of the freshness indices, indicative of a reduction of methanethiol and loss of freshness with time. In contrast, the capsule C4 that has a $100 \%$ aluminum body and aluminum cover hardly shows any evolution of both freshness indices over the 46 weeks of storage.
We conclude that $\mathrm{C} 4$ preserves the freshness of coffee much more efficiently. $\mathrm{C} 3$ takes an intermediate position, with respect to the evolution of the freshness indices. This is in line with the fact that C3 has a PP body (no aluminum) and a cover with a thin aluminum layer. In addition it is wrapped into a secondary aluminum packaging. Clearly, the absence of aluminum has a strong impact on the loss of freshness-indices for $\mathrm{C} 1$ and $\mathrm{C} 2$. Secondly the starting value of the freshness indices varies among the four different capsule systems. While C4 starts already at a high value, $\mathrm{C} 1$ has the smallest freshness indices for dimethyl disulfide/methanethiol and 2-butanone/methanethiol. It is speculated that this is an indication of a certain loss of aroma from processing prior to packaging into capsules. Thirdly, the consistency among capsules appeared to differ strongly. Each capsule was measured in five repetitions and data are plotted in Fig. 2 as mean value $\pm 68 \%$ confidence interval. The standard deviation revealed an unexpected and interesting insight into the consistency of the coffee in the various capsule systems. C4 showed the smallest confidence interval, which is an expression of low capsule-to-capsule variability. In contrast, C1 and C2 show much greater variability among capsules. Particularly for single serve capsules, where a whole range of capsules are offered by each brand, consistency is an important quality criterion. Research is ongoing to verify whether these findings on roast and ground are also reflected in the final cup of coffee.

\section{Conclusions}

With the rise of specialty coffee and the mounting focus of quality, freshness is becoming a critical attribute. Loss of freshness may be related to either loss of VOCs through evaporation or chemical reaction with oxygen and other coffee components. This leads to a change in the balance of the VOCs (changes in the relative headspace concentrations of VOCs). In order to best monitor such changes, and concomitantly probe the loss of freshness, one can either measure the absolute concentration of specific VOCs in the headspace, which is laborious and requires quantification and calibration. Here, an alternative approach was taken. Ratios of headspace intensities were measured, as these are more robust (less dependent on variables such as blend, roast degree, grinding, extraction ore other) and less tedious to be measured analytically.

We have presented four different freshness indices, two for roasted whole beans and two other for single serve $(R \& G)$ coffee capsules. The roasted whole beans, coffea arabica from 
Guatemala, Antigua (La Ceiba), were packed with four different packaging materials, in $250 \mathrm{~g}$ pack sizes. The single serve capsules were commercial products from the Swiss market. All coffees were stored at room temperature.

Two freshness-indices were discussed for roasted whole beans: 2-butanone/2-methylfuran and 2,3-butanedione/2methylfuran. The most significant insight was that the presence of aluminum as a packaging barrier material strongly preserves the freshness of coffee. For single serve capsules, two different ratios were presented: dimethyl disulfide/methanethiol and 2-butanone/methanethiol. The results revealed that: i) the capsule $\mathrm{C} 4$ that is entirely made of aluminum, best preserved the freshness of coffee in the capsules. In contrast, the two capsules $\mathrm{C} 1$ and $\mathrm{C} 2$, with no aluminum barrier, preserved less freshness over time. Capsule $\mathrm{C} 3$, which had a PP body, but an aluminum secondary packaging, exhibited an intermediate protection. ii) Differences in the starting values of the freshness indices were noticed. While this may be attributed to differences in the coffee (variety, roast, ground...) it is speculated that a higher starting point in the ratios is due to differences in the processing prior to packaging into the single serve capsules. iii) Finally, the standard deviations are indicative of the variability (or consistency) of the capsules. Capsule $\mathrm{C} 4$, with the smallest standard deviation (in five repetitions), had the highest consistency relative to the other capsule systems.

\section{Acknowledgement}

The present work was only possible thanks to the support of Rast Kaffee AG in Ebikon, Switzerland (whole roasted beans) and Luna Technology Systems LTS GmbH in Wallisellen, Switzerland (coffee capsules).

Received: January 27, 2014

[1] R. Zimmermann, H. J. Heger, C. Yeretzian, H. Nagel, U. Boesl, Rapid Commun. Mass Spectrom. 1996, 10, 1975.

[2] 'Flavour Release', Eds. C. Yeretzian, A. Jordan, H. Brevard, W. Lindinger, D. D. Roberts, A. J. Taylor, ACS Symposium Series 763, Washington, DC, ACS, 2000, 112-123.

[3] R. Dorfner, T. Ferge, A. Kettrup, R. Zimmermann, C. Yeretzian, J. Agric. Food Chem. 2003, 51, 5768.

[4] R. Dorfner, T. Ferge, C. Yeretzian, A. Kettrup, R. Zimmermann, Anal. Chem. 2004, 76, 1386.

[5] F. Wieland, A. Gloess, M. Keller, A. Wetzel, S. Schenker, C. Yeretzian, Anal. Bioanal. Chem. 2011, 402, 2531.

[6] A. N. Gloess, A. Vietri, S. Bongers, T. Koziorowski, C. Yeretzian, Association Scientifique Internationale du Cafe, $24^{\text {th }}$ Colloque Scientifique International sur le Cafe, 2012.

[7] F. Wieland, A. N. Gloess, M. Keller, A. Wetzel, S. Schenker, C. Yeretzian, Chimia 2012, 66, 443.

[8] R. Hertz-Schünemann, R. Dorfner, C. Yeretzian, T. Streibel, R. Zimmermann, J. Mass Spectrom. 2013, 48, 1253.
[9] I. Blank, A. Sen, W. Grosch, Z. Lebensm.-Unters. Forsch. 1992, 195, 239.

[10] W. Holscher, H. Steinhart, Z. Lebensm.-Unters. Forsch. 1992, 195, 33.

[11] P. Semmelroch, W. Grosch, Lebensm.-Wiss. u. -Technol. 1995, 28, 310.

[12] M. Czerny, R. Wagner, W. Grosch, J. Agric. Food Chem. 1996, 44, 3268

[13] P. Semmelroch, W. Grosch, J. Agric. Food Chem. 1996, 44, 537.

[14] M. Czerny, F. Mayer, W. Grosch, J. Agric. Food Chem. 1999, 47, 695.

[15] F. Mayer, M. Czerny, W. Grosch, Eur. Food Res. Technol. 2000, 211, 272.

[16] W. Grosch, 'Coffee: Recent Developments', Blackwell Science, London, 2001, Chapter 3, pp 68-89.

[17] F. Mayer, W. Grosch, FFJ. 2001, 16, 180.

[18] I. Blank, E. C. Pascual, S. Devaud, L. B. Fay, R. H. Stadler, C. Yeretzian, B. A. Goodman, J. Agric. Food Chem. 2002, 50, 2356.

[19] L. J. Munro, A. Curioni, W. Andreoni, C. Yeretzian, H. J. Watzke, J. Agric. Food Chem. 2003, 51, 3092.

[20] T. Karl, C. Yeretzian, A. Jordan, W. Lindinger, Int. J. Mass Spec. 2003, 223, 383

[21] P. Pollien, A. Jordan, W. Lindinger, C. Yeretzian, Int. J. Mass Spec. 2003, $228,69$.

[22] H. D. Belitz, W. Grosch, P. Schieberle, 'Food Chemistry', Berlin, Heidelberg, New York, 2004, p 1077.

[23] A. C. Shuman, L. W. Elder, Ind. Eng. Chem. 1943, 35, 778.

[24] M. C. Merritt, B. A. Cawley, E. E. Lockhart, B. E. Proctor, C. L. Tucker, Food Technol. 1957, 11, 586.

[25] N. Buchner, R. Heiss, Verpackungs-Rundschau 1959, 10, 73.

[26] J. C. Spadone, R. Liardon, ASIC-13eme Colloque Scientifique International sur le Café, Paris, ASIC, 1990, pp 145-157.

[27] T. Arackal, G. Lehmann, Chem. Mikrobiol. Technol. Lebensm. 1979, 6, 43.

[28] K. Marin, T. Požrl, E. Zlatic, A. Plestenjak, Food Technol. Biotechnol. 2008, $46,442$.

[29] H. Kallio, M. Leino, K. Koullias, S. Kallio, J. Kaitaranta, Food Chem. 1990, 36,135 .

[30] M. Leino, J. Kaitaranta, H. Kallio, Food Chem. 1992, 43, 35.

[31] W. Holscher, H. Steinhart, Lebensmittelchemie 1992, 46, 106.

[32] H. Steinhart, W. Holscher, ASIC-14eme Colloque Scientifique International sur le Café, Paris, ASIC, 1992, pp 156-164.

[33] R. A. Buffo, C. Cardelli-Freire, Flavour Fragr. J. 2004, 19, 99.

[34] R. Massini, M. C. Nicoli, A. Cassara, C. R. Lerici, Ital. J. Food Sci. 1990, 2 , 123.

[35] M. Anese, L. Manzocco, M. C. Nicoli, J. Agric. Food Chem. 2006, 54, 5571.

[36] M. Nicoli, S. Calligaris, L. Manzocco, Food Eng. Rev. 2009, 1, 159.

[37] C. F. Ross, K. Pecka, K. Weller, J. Food Qual. 2006, 29, 596.

[38] M. C. Nicoli, N. Innocente, P. Pittia, C. R. Lerici, ASIC 15th International Scientific Colloquium on Coffee, 1993, pp 557-566.

[39] R. Radtke, R. Springer, W. Mohr, R. Heiss, Z. Lebensm.-Unters. Forsch. 1963, 119, 293

[40] H. Ito, S. Atsuta, K. Shibata, M. Shimoda, Y. Osajima, Nippon Shokuhin Kogyo Gakkaishi 1983, 30, 435.

[41] M. Vila, S. Andueza, M. Paz de Peña, C. Cid, JAOCS. 2005, 82, 639.

[42] W. Holscher, O. G. Vitzthum, H. Steinhart, Café Cacao Thé 1990, 34, 205.

[43] M. Czerny, P. Schieberle, ASIC-19eme Colloque Scientifique International sur le Café, Paris, ASIC, 2001, pp 1-6.

[44] H. Kallio, M. Leino, L. Salorine, J. HRC \& CC 1989, 174.

[45] O. G. Vitzthum, P. Werkhoff, Chem. Mikrobiol. Technol. Lebensm. 1979, 6, 25.

[46] J. Baggenstoss, F. Escher, 'Expression of Multidisciplinary Flavour Science - $12^{\text {th }}$ Weurman Symposium', Zurich University of Applied Science, Wintherthur, 2010, Chapter 6, pp 271-274.

[47] H. W. Chin, R. C. Lindsay, J. Agric. Food Chem. 1994, 42, 1529. 